\title{
Assessing some of the regulatory approaches to transgenic plants: What can we learn from the regulation of other technologies?
}

\author{
Carl F. CRANOR* \\ Department of Philosophy, University of California, Riverside, CA 92521, USA
}

Transgenic plants result from the isolation and insertion of genes into plants by means other than conventional breeding techniques, making it possible to isolate a gene that controls a valuable trait without also inserting thousands of other genes, as can occur with other methods. Transgenic plants potentially can provide substantial benefits to humans, but they can also pose risks to ecosystems, nontarget species and even to humans. I utilize the U.S. regulatory experience with chemical substances to provide some background for locating the strengths and weaknesses of different legal structures as well as providing an opportunity to learn from them. Learning from that case study and different legal structures utilized therein, as well as from the state of the world in which transgenic plants will be introduced and the state of the relevant sciences combined with a National Research Council Report on transgenic plants, this essay assesses the regulatory procedures that the U.S. Department of Agriculture uses to evaluate the risks from transgenic plants. These legal structures, although well suited for identifying risks before there is extensive exposure, have a number of shortcomings for reviewing the products of a new and not well-understood technology. The U.S. could take some steps toward improving its reasonable, tiered, pre-market approach for reviewing the risks from transgenic plants by following the NRC recommendations and learning from shortcomings of the regulation of chemical risks. Whether it will be or not remains to be seen.

Keywords: transgenic plants / chemical risks / risk assessment / laws for assessing and regulating risks

\section{INTRODUCTION}

Transgenic plants result from the isolation and insertion of genes into plants by means other than conventional breeding techniques (NRC, 2002, p 43). It is, thus, possible to isolate a gene that controls a valuable trait without also inserting thousands of other genes, as is the case in conventional breeding from species that are not sexually compatible with the recipient (horizontal gene transfer). The promise of transgenic technologies is that novel phenotypic traits can be introduced into agricultural crops that "will improve their yield, their resistance to biotic and abiotic stresses, their biochemical composition, their shelf life and other traits" (NRC, 2002, $\mathrm{p}$ 43). They promise assistance in feeding an everincreasing world population, possibly improving health (with vitamin A enriched plants), and lessening adverse impacts on the environment by reducing the use of chemical pesticides. Such processes are thought to be faster, more accurate and more flexible than conventional breeding processes.

Transgenic plants also have their risks. There may be crop-weed genetic movement creating a new weed that has a competitive advantage over domestic crops. Even with traditionally improved crops, crop-wild hybridization has created problems. A natural hybrid of wild beets and sugar beets has presented a problem for Europe's sugar industry. Crop-wild plant gene flow can send "a rare species to extinction in a few generations" (Ellstrand, 2001). Some unintended transgene movements might inadvertently poison beneficial insects or other non-target species, while others could contaminate food intended for human consumption, the potential of which was revealed by the recent Starlink contamination of corn. The use of

\footnotetext{
* Corresponding author: carl.cranor@ucr.edu
} 
viral vectors for inserting genes might pose health risks to humans or animals (NRC, 2002, p 110). Undesirable gene flows can result from either conventionally bred or transgenically created plants (Ellstrand, 2001).

How might many of these adverse effects be avoided or at least be reduced? What legal structures could be utilized to identify such risks earlier and reduce or avoid them? How would different legal structures affect the innovation of new products?

This essay takes some steps toward addressing these questions in considering current regulations governing transgenic plants. First, it seeks to learn from the history of the mature synthetic chemical industry and its legal regulation. While the technologies or threats from transgenic plants are hardly identical to those of synthetic chemicals, we can learn much from the legal structures utilized to inform us about and to regulate synthetic chemicals. One approach might be to assess the risks from transgenic plants as they appeared after the plants were in the market, a "post-market" approach similar to that used to address most chemical risks. However, as I argue in the second section such legal strategies have significant shortcomings even for chemical regulations and stand in need of improvement to address some of the risks of a quite new technology. Another approach would be to screen new products before they enter commerce in order to try to identify risks before people and the environment are exposed to them. Such statutes would likely prove a better method for regulating risks, but may slow the innovation of new products. Further, both the ecological and human contexts into which products will be introduced are important considerations bearing on how new technologies are addressed legally. And, the state of scientific knowledge about the natural environment and scientific knowledge about the developing technology bear on which legal strategies might be adopted. Finally, I will draw on a recent report by the National Research Council, "Environmental Effects of Transgenic Plants: the Scope and Adequacy of Regulation," to provide some background about the existing pre-market legal structure for regulating transgenic plants and to assess aspects of the current U.S. approach toward regulating transgenic plants.

\section{LESSONS FROM REGULATING SYNTHETIC CHEMICALS: INFORMATIONAL AND LEGAL SHORTCOMINGS}

Before considering more directly the regulation of risks from transgenic plants, I believe it is useful to reflect on a more familiar technology with which the U.S. society has had considerable experience. This provides legal context for locating genetic regulations and we can learn from the legal and scientific experience of a mature industry such as the synthetic chemical industry to guide assessment of legal structures. This alerts us to some issues that might result from an emerging technology such as transgenic plants, suggests some shortcomings with some existing legal structures, and indicates some generic approaches to improve legal structures for a new technology.

Concerns from this history of synthetic chemical regulation fall into several categories. The first includes actual harms to the environment and human health that have arisen from chemical technologies. A second focuses on extensive informational deficiencies that exist with respect to the universe of created chemical substances, and a third results from delayed responses to problems or legal strategies that frustrated or slowed protective actions (Cranor, 2003b).

Some products or technological by-products of the synthetic chemical industry caused actual harm - DDT, chlorofluorocarbons, PCBs, lead, mercury, cadmium, nickel, benzene, asbestos, DES, and other toxicants, as well as disposal practices that created toxic soups in waste sites have caused human health or environmental damage. When some of these products were introduced, the toxicological sciences may not have been well enough developed to identify the risks involved. Early on there may have been so little testing of products that they were not well enough understood to identify potential harms. Finally, existing institutional structures may have been inadequate to encourage the early identification of risks and harms. However, for some of the products that were developed later, similar risks and harms became apparent, but the legal response was too little, too late, or inadequate. Moreover, although there is an individual story for each substance that caused each kind of harm, in many cases early or even late warnings were ignored resulting in significant social mistakes (European Environmental Agency, 2001). How can more of these warnings be heeded in the future and analogous mistakes be avoided for new technologies?

In other cases, it is not necessarily that harms have occurred, but that the scientific and regulatory communities as well as the public have so little understanding of the properties of the vast majority of substances and their consequences. Over time, of course, what we don't know may harm us. Indeed often the public and regulatory agencies have been surprised by the appearance of toxicants, sometimes surprised by products that have presumably been well-reviewed under 
Transgenic plants: learning from the regulation of other technologies

pre-market statutes, e.g., therapeutic drugs (Green, 2000).

In general there appears to be paucity of evidence about the universe of chemical substances. There are about 20500000 unique organic and inorganic chemicals (Huff and Melnick, 2002). A subset of these, about 100000 substances and their derivatives, are registered for commerce, many of which are in common use in the U.S. (Huff and Melnick, 2002), with another 800-1000 added to the list each year with minimal or no pre-market testing (U.S. Congress, 1987).

Scientists appear to know little about the 100000 substances registered for commerce. In 1984 the U.S. National Academy of Sciences found that there were 12860 substances produced in volumes exceeding one million pounds per year for $78 \%$ of which there is no toxicity information available and another 13911 chemicals produced in volumes of less than 1 million pounds for $76 \%$ of which there was no toxicity data. Beyond these general facts, there were 8627 food additives (46\% with no toxicity data), 1815 drugs (25\% with no toxicity data), 3410 cosmetics (56\% with no toxicity data), and 3350 pesticides ( $36 \%$ with no toxicity data) (NRC, 1984, p 11). For foods, drugs, cosmetics and pesticides one might expect closer scrutiny because most of them enter the human body or come in close proximity to it, and, while the ignorance of the toxicity properties of these products is not as profound as the general record, it is not encouraging. Moreover, in the early 1990s there were not sufficient changes in the data to justify updating the National Academy Report (Bailor, 2002). For 3000 substances produced in the highest volume, a subset of the 12860 (above), 75\% of them had significant knowledge-gaps as recently as 1998, when the U.S. EPA entered into an agreement with the producers to close the knowledge gaps (Environmental Health Letter, 1998). Finally, the Office of Technology Assessment reported that there are another 1000-12 000 for which extensive toxicological information would be quite important but which is not available (U.S. Congress, 1995, p 2).

A reasonable lesson from this background is that free enterprise institutions, operating in the exiting legal environment, created, introduced and distributed chemical substances without developing sufficient information about their consequences for human health and the environment and sometimes ignoring existing evidence. Moreover, firms created new substances much faster than the toxicological community could understand and characterize their properties and legal institutions could regulate them. In addition, some firms themselves have added to the problem by deliberately keeping information from agencies or falsifying data, etc. (Berger, 1997, p 2133; Markowitz and Rosner, 2002).

Some of the ignorance of synthetic chemicals might have resulted when the science of toxicology was so new that many risks went undetected. Some of it resulted from a free enterprise system that began creating and introducing synthetic substances before more protective regulations were enacted in the early 1970s. However, part of it is probably traceable to the inadequacies of the legal strategies themselves that were adopted in the early 1970s. It is these that we should address and learn from as new technologies are being developed and that will improve the identification of risks and their regulation. Unless one assumes that the regulation of chemical products was ideal or that these products received just the right amount of legal scrutiny given the risks, harms and costs involved, we should learn from this experience and improve on it for addressing new technologies. What can we reasonably learn from this sketch of legal structures governing chemical substances for addressing transgenic plants?

With an emerging technology, such as transgenic plants, it seems important that 50 years from now the U.S. not have similar ignorance about their properties and environmental and health consequences from exposure to thousands of transgenic plants. Moreover, these concerns are underlined when we realize that plants have some properties that make them much more worrisome than synthetic chemical substances: they can procreate, migrate, and mutate; even genes can transfer from one organism to another (Ellstrand, 2001). These properties of transgenes suggest that they might be more difficult to control and contain than synthetic chemical substances; what their ultimate adverse consequences might be depends upon their properties.

\section{MODELS FOR ADDRESSING RISKS FROM NEW TECHNOLOGIES}

Elsewhere I have articulated a model for the primary prevention of human health and environmental harms in order to provide a foil against which to evaluate legal structures and the extent they protect against risks and harms (Cranor, 2003b). The aim of that exercise was to focus on legal strategies that had as their goal identifying risks and preventing them from materializing into harm. Having such a model provides us with insight into what we may be missing in current legal structures or how they can be improved in order to do a better job in the future of identifying and responding to risks. By a primary prevention strategy I mean one that aims to identify 
substances that will pose risks and screen them out before there is significant human or ecological exposure to them, or at least before significant harm materialized. A second best legal strategy might be one that sought to identify risks after there was human and environmental exposure, but to identify them in such a way that the risks would not materialize into harm. A third best strategy might be one in which, although there was exposure to humans and the environment, and although there were risks, one would seek to monitor the people or environment exposed in order to identify as early as possible any evidence that risks were materializing into harm, and then respond expeditiously when such evidence existed. This strategy resembles the medical monitoring that can be required under regulatory statutes for employees already exposed to dangerous substances or medical monitoring that can be a legal cause of action in the tort law separate from an action for actual harm suffered.

These different generic strategies have different strengths and weaknesses attached to them. Strategies that have as their aim the primary prevention of harm are more successful in identifying and screening out risks before there is exposure or before actual harm results, but they typically burden innovation, product development and perhaps overall wealth creation. Strategies that rely upon surrogates for human and environmental risks to identify risks before they materialize into harm permit faster innovation, faster introduction of products, and perhaps greater wealth creation, but typically would fail to detect as many risks before humans or the environment are exposed to them or be as successful in avoiding harm.

\section{Pre-market screening strategies}

A model legal strategy that is based upon the idea of a good pre-market screening statute (a reasonably successful legal strategy from the past), analogous in the U.S. to the Food, Drug and Cosmetic Act (addressing food additives, drugs, and cosmetics) or the Federal Insecticide, Fungicide and Rodenticide Act (which addresses pesticides), highlights a more protective approach toward preventing human health and the environmental risks and harms than other approaches. A pre-market law for human health protections seeks to identify substances that would pose risks or cause actual harms before they occur and screen them out so that there is no exposure to them or so that any exposures are so low that the resulting risks are diminimis or non-existent. I have argued elsewhere that such an approach would have the following features.
It would place on the manufacturer of a product or substance a reasonable burden to produce evidence about the short- and long-term human health and environmental effects of substances or products that would enter commerce. It would place a burden of persuasion on the firm to show to some standard of proof to the satisfaction of an agency, analogous to the U.S. Food and Drug Administration, that the substance or product was appropriately "safe" or posed no "significant risks" (where these would need specification) to the public, the workforce or the environment. The substance would not enter commerce until it had agency review and approval that it was "safe" or posed "no significant risks." The product's continued presence in the market would be conditioned on its being "safe" or exhibiting "no significant risk." It could be expeditiously withdrawn if evidence arose that falsified the condition of approval. Moreover, the firm would have an affirmative legal duty (not left to voluntary compliance) to report evidence of adverse effects to the agency (Cranor, 2003a).

For such a law to function well, it must be appropriately funded and conscientiously applied.

The model has several attractive features. It places on manufacturers a requirement to generate information about human health and environmental effects of their products contemporaneous with the product's creation. It provides that there is no or very little health and environmental exposure to substances until an agency is satisfied that there are no risks or no unacceptable risks from them and permits them into production and commerce. It authorizes expedited withdrawal of products from the market when adverse reaction reports show that the condition of approval no longer obtains. Finally, it imposes on a firm an affirmative duty to compile and report data about adverse effects once the product is in the market (Cranor, 2003b).

Thus, it has many features that are aimed at preventing risks in the first place (pre-market screening) or if that fails, it has provisions to rectify screening failures (expedited withdrawal) and features to try to identify longer-term toxic features of substances that inevitably will be missed even with pre-market screening (post-market reporting).

Moreover, such pre-market statutes could be structured for different products and different risks. The structure would have different "tiers" with different "requirements" for testing, product review and approval, depending upon the extent and significance of risks presented, provided scientific research would support 
Transgenic plants: learning from the regulation of other technologies

such differentiation. For example, in the chemical area if there were some scientifically well founded and defensible way to identify substances that would be comparatively safe, as, for example, large polymer molecules tend to be, there would be little reason to screen such products stringently, or perhaps they would not need pre-market screening (Eastmond, 2002). By contrast, if there were other classes of chemicals whose properties were toxicologically or environmentally suspect, e.g., strong mutagens tend to pose serious health risks or substances that tend to bind to DNA, this would provide reasons for screening them much more carefully and for their having to overcome a much higher standard of proof before they could enter commerce. Such differential screening depends upon there being sufficient scientific knowledge to make accurate discriminations between different levels of risk. Whether or not there is an adequate scientific basis for this in a particular product area is an issue that must be addressed for the products in question. This is an issue concerning transgenic plants.

Despite their attractiveness, pre-market strategies are not a panacea. For one thing, although pre-market screening approaches promise the best means for identifying risks and preventing harm, they are not without costs. For example, products subject to such laws must have substantial research into their risks (a desirable feature) and often their efficacy. However, a typical complaint is that extensive pre-market safety testing is a substantial added cost over and above the normal costs of product development. The extent to which such testing is needed depends upon the properties of the substance and the human or environmental exposures that will result. Products subject to pre-market review also typically undergo varying degrees of pre-market review, which tends to slow their entry into the market and, thus, to slow the realization of any benefits accompanying them. Currently, under the U.S. Food, Drug, and Cosmetic Act, some drugs that require pre-market testing and review have been approved under so-called "fast track" procedures in recent years in order to speed up the review process, but this has resulted in the approval of a number of drugs that had quite serious side effects. A substantial number of these had to be withdrawn (Green, 2000). Thus, premarket reviews can be too fast. Beyond mistakes from too rapid a review (which could be corrected), a more endemic and intractable testing problem, however, is that even extensive human clinical trials on small groups of people may be inadequate to ferret out all or even most adverse effects of a drug that is marketed to a diverse population of millions of people (Green, 2000). The fact that there are such intractable problems from the logic of testing suggests that there is a significant need even with pre-market statutes for followup to the initial approval and continued tracking of the products. Such laws should have provisions for companies to report adverse reactions during post-market commercialization and provisions for relatively quick withdrawal from the market if serious risks or harm associated with the drugs develop.

\section{Post-market laws - the need for significant augmentation}

I began with a model pre-market law, not only to have a foil for what we might be missing in pre-market contexts, but also to provide a kind of model for identifying deficiencies in how post-market statutes tend to approach the identification and regulation of risks. The pre-market foil can also suggest how post-market laws might be improved to better identify and catch risks than some have to date, even if post-market laws were on balance superior because of their effects on innovation or on some other dimension.

Post-market strategies toward identifying and regulating risks typically permit substances to enter commerce with no required testing, no pre-market screening and approval, but ideally would authorize the use of surrogates for human health or environmental risks in order to identify and remove the risks before they materialized into harm. (A post-market strategy that waited for human or environmental harms to occur could hardly be said to be protective, except in the sense that it might avoid greater catastrophes.) Thus, for example, in the human health area, such statutes might explicitly authorize the use of animal studies or even various short-term tests to identify with sufficient accuracy substances that would likely cause harm to humans. The aim, of course, would be to utilize non-human evidence of various kinds in order to identify likely human risks before they materialized to cause actual harm. This is an obvious strategy, but one which is always at risk of being eroded in the U.S. regulation of synthetic chemicals (Cranor, 2003a).

One downside to post-market statutes is that humans or the environment in effect might come to be used as the laboratory in which products are tested, if there is insufficient attention to the risks of products before actual harm occurs, or if the use of surrogates is so diminished that agencies require human evidence of harm before regulation occurs.

In addition, under post-market laws if humans and the environment are not to be guinea pigs, there need to be various post-market information-generation strategies 
(to remedy targeted information deficiencies) as well as various expedited protective responses when evidence of toxicity effects appear. For example, in generating information about products in order to avoid surprises firms might be required to generate toxicity data about their products once production exceeded some specified volume, e.g., 100000 pounds per year (since this would ceteris paribus result in greater exposures and more harm if the substances were harmful). (An analogue for transgenic crops might be to require testing if plantings larger than certain acreages were exceeded.) Or, as under California's Proposition 65 if substances were identified as being in certain classes of toxicants, such as being carcinogenic or reproductive toxicants, then the firms using or manufacturing them might then be obligated to show that there was no significant public exposure or that the substances did not appear in specified concentrations in the environment (Cranor, 2003a).

Beyond generating information, if post-market statutes are to provide protections without using the populace or the environment as the laboratory, they should also permit relatively quick protective responses once toxicity or other adverse effects are identified in the post-market context. Such a provision assists in reducing the amount of harm that risks cause when they materialize into harm.

There are two further disadvantages of post-market legal structures. One is that because they are typically utilized by placing a burden of proof on a governmental entity to produce information to justify regulating or removing the product from market, a firm that might be subject to such an action has incentives not to test and not to produce information that can be used against it in a legal proceeding. Consequently, typical post-market laws do not have good incentives for firms to produce needed information on health and environmental impacts of its products.

A further disadvantage of post-market strategies is that knowledge asymmetries and sluggish legal reactions to actual harm can be greatly exacerbated by the norms of scientific epistemology insofar as scientific information about adverse health or environmental effects must be generated before removing a product or reducing exposure to it. Scientific research is data- and laborintensive, as well as more concerned with preventing false positives results from studies and inferences than with preventing false negatives (Cranor, 1999). Thus, it will be difficult or impossible to close these knowledge gaps in any expeditious manner, if a governmental agency has the burden to demand or to produce it. In addition, a standing temptation of scientific research to demand more and better evidence before drawing a conclusion with respect to adverse effects exacerbates the problem (Cranor, 1993).

A post-market approach, if it worked well, were fully supported, and were reserved for products either that were very unlikely to produce risks or such risks could be easily identified as, for example, many mechanical risks can be, might provide significant protections for human health and the environment. However, the experience with chemical regulation suggests that post-market strategies have tended not to work well, especially in generating needed information. A large number of substances for several reasons enter commerce without adequate toxicity data, and those risks must be identified after entering commerce. There are incentives for firms to resist providing needed information and to resist regulation. There is a tendency of firms to urge (and agencies to acquiesce in) basing regulation on human or ecological harms (thus defeating the ideal of using reasonably accurate surrogates to identify the risks of harms earlier). And, often agencies are slow to act once risks have be reasonably well identified (Cranor, 2003b).

What can we conclude from the review of legal strategies? Preventive pre-market strategies provide the greatest protections from risks and harms, but these can slow the entry of products into market because of the need for agency review over and above any testing that needs to be done. One might think that ideally firms should be doing the same safety testing no matter what legal environment their products are subject to. However, it appears that insufficient testing is done if products are permitted to enter commerce without being subjected to pre-market review. Consequently, if post-market legal strategies are to be utilized and to reasonably approach some of protections from risks and harms that a good premarket strategy would provide, then a society must find the right mix of strategies from pre- and post-market devices to achieve the right balance of protection and encouragement of innovation. There are a variety of ways this could be accomplished, but one that suggests itself is that if there were a general case for encouraging innovation, but also a commitment to try to identify most risks before they materialized into harm, a society could require some testing of substances to rule out the most toxic features, have them submitted to an agency with a pre-market notification statute, and the information along with it, and then permit the substances into commerce with comparatively short regulatory review. However, a post-market legal strategy could then require considerably more testing if production volume exceeded some large amount, continued monitoring of the health 
Transgenic plants: learning from the regulation of other technologies

and environmental effects, and expedited recall of the product if there were was sufficient evidence of risks posed, where the threshold for needed evidence was easier to meet than under many existing post-market statutes in the U.S.

Which of these strategies one might adopt for a particular technology would depend upon the technology, the extent to which a society aimed to ensure a high degree of innovation (with a higher tolerance for risks that would result), how well the technology was understood and the condition of the environment or public health into which it was could enter.

\section{THE EXISTING LEGAL STRUCTURES FOR TRANSGENIC PLANTS AND AN ASSESSMENT}

What can we learn from the lessons of the regulation of synthetic chemicals and the discussion of different legal strategies for reviewing and assessing the safety of transgenic plants, the incentives they create and how a legal system might approach the regulation of a new technology such as transgenic plants? Before turning to the existing legal structure for transgenic plants and some assessment of it, two further generic considerations should be briefly reviewed.

\section{Context in which new technologies are introduced}

One consideration is the human and environmental context into which a product is introduced. The National Research Council has pointed out that new plant species (genotypes), whether produced by conventional or transgenic processes, might adversely affect existing agricultural crops or natural ecosystems. The NRC argues that there is "substantial evidence" that farming itself exerts "simplifying and destabilizing effects on neighboring natural ecosystems" which in turn can "weaken or destroy ... an ecosystem's ability to return to its initial state despite disturbance" (NRC, 2002, pp 3, 4). For example, the conventionally bred semi-dwarf, shortseason varieties of rice and wheat that created the Green Revolution resulted from a single gene change for short stature and a few gene changes for "more rapid maturation." Large-scale farms with these plants resulted in "massive changes in agricultural practices that increased production" (NRC, 2002, pp 4, 5). These in turn "increased soil salinity, lowered water tables, and altered wetlands in some regions" (NRC, 2002, p 5). The potential effects of transgenic corn that produces its own pesticide may pose threats to other species such as the monarch butterfly (Sears et al., 2001). Consequently, in such situations the "[p]otential ecological effects of transgenic crops, and other crops bearing novel traits, may be heightened. ... This argues for a cautious approach to the release of any crop that bears a novel trait" (NRC, 2002, p 4).

This point is, I believe, well taken. If a new product enters an environment that is robust, highly resilient and quite capable of prospering despite some insults, a society may be able to tolerate a wider range of risks than in circumstances in which the same environment were weakened, much less resilient, and less capable of prospering in the face of insults. The relevant scientific question is what is the condition of the farming and natural environments at this time when transgenic plants are being considered for introduction, but one I am not in a position to address.

The possible ecological effects about which the NRC is concerned are even more sobering when considered against some general facts about the current condition of the broader environment. Comparatively pristine air, water, oceans, and wilderness are vanishing or are on their way to vanishing. In the past 50 years the world's forested lands have shrunk substantially (Rodgers, 1994, p 8). Water tables are falling around the world; humans are over-pumping aquifers in China, India, North Africa, Saudi Arabia and the U.S. by about 160 billion tons of water per year, enough from non-renewable sources to produce food for 480 million people per year, a simply unsustainable rate (Brown et al., 2000, pp 6, 7). About "two thirds of major marine fisheries are fully exploited, overexploited or depleted" (Lubchenco, 1998, p 492), with recent reports suggesting that whole fishery areas of the ocean must be given a chance to regenerate or they may be lost forever. About 11 percent of bird species, 25 percent of mammal species and an estimated 34 percent of all species are vulnerable or in immediate danger of extinction (Brown et al., 2000). Some tropical forests have been turned into "inferior, rapidly degrading pasture" with attendant loss of biodiversity (Rodgers, 1994, p 24). The world's population, which has more than doubled in the lifetime of readers older than 40 and which is projected to increase about $50 \%$ in the next 50 years, will greatly exacerbate the above problems and put additional stresses on the environment (Rodgers, 1994, p 3).

It is difficult to determine how fragile or how resilient the ecosystems of the world are. However, if introduced plants can have substantial destabilizing effects on natural systems, and even greater effects on ecosystems 
weakened by agriculture as well as general human impacts, as the NRC indicates, this context suggests that humans should exercise considerable caution in introducing novel genetic traits into an environment that has potentially fragile segments. The NRC importantly notes that both conventionally bred as well as transgenic plants have the potential to cause substantial environmental problems: the movement of transgenes, escape of whole plants, impacts on agricultural practices, non-target organism effects and resistance evolution can result from both processes (NRC, 2002, p 7). It is not the process by which the genes of plants are altered, but the risks posed by the resulting product (NRC, 2002, p 5). Thus, the Academy suggests a careful approach toward the introduction of plants with novel genetic traits and recommends reviewing transgenic plants on a caseby-case basis, neither giving them blanket approval nor blanket condemnation because they result from transgenic processes.

It is also important, however, to notice that transgenic plants will not exacerbate all the ecological conditions reviewed above, but will affect only some of them. Moreover, in a few cases transgenic plants might assist in addressing some of the ecological problems, e.g., with the development of drought-resistant plants, although it is not clear how optimistic one should be on this issue, given the experience with the "green revolution" noted above.

\section{The state of the relevant scientific knowledge}

Another consideration that is pertinent to creating a legal structure to regulate the introduction of a new technology is the extent to which a technology is well or poorly understood. For example, if it were possible for researchers to relatively easily and fully understand a technology and it various uses, as at least in retrospect it might seem that we understand the technology of the industrial revolution (because these are machines whose behavior we can observe), then there might be a lesser need to screen innovative products by means of the pre-market screening process. By contrast, to the extent that a technology and the context into which it will be introduced are poorly understood by scientists, this would provide reasons for going more slowly and carefully until the technologies are much better understood.

The argument in the preceding paragraphs is strengthened for transgenic plants by considerations concerning the scientific understanding of the environment into which novel genetic traits might be introduced and the state of genetics. Although genetics has come a long way since the discovery of the double helix, the NRC in several places recognizes that the scientific understanding of both "genetics and ecology is still developing" (NRC, 2002, p 184). In addition, the NRC points out that "our collective judgments of environmental impacts" have changed over time and the information necessary to make good judgments about environmental risks from transgenic plants "is like a moving target" (NRC, 2002, p 188). Moreover, a "much broader array of phenotypic traits can now potentially be incorporated into plants than was possible two decades ago" and this is likely to increase dramatically with transgenic plants (NRC, 2002, p 14). Once a plant and its transgenes risk being used "for purposes other than originally intended" and for which they have been approved, they could pose substantial problems. For example once a plant is approved for general release and is subject to no further regulation (a possibility within the current legal structure (more below)), "a selectable marker transgene that confers herbicide tolerance in a deregulated [plant] could be transferred to another variety or another species to create a new variety to be sold as a herbicide-tolerant product" (NRC, 2002, p 184).

The issue is that because scientists do not yet understand well either the impacts of introduced species on ecosystems or genetics and its ramifications, and since it is difficult to determine what information is needed to fully assess such risks, it appears that such decisions will be made under substantial uncertainty and in considerable ignorance (European Environmental Agency, 2001). If such decisions could have quite serious adverse consequences, this argues for making them cautiously, with considerable humility and with a full range of scientific expertise (currently lacking) in order to ensure that they are appropriately protective of ecosystems and species within them. As I review below the current Department of Agriculture's procedures appear to have a number of problems for reviewing well the risks from transgenic plants.

In view of the "developing" understanding of both genetics and ecosystems, the NRC notes the importance of a case-by-case assessment of transgenic plants, especially for those plants for which "non-regulated status" (developed below) is sought, because "each plant/ trait/environment combination is different."

\section{Aspects of the current U.S. legal structure for regulating transgenic plants}

There is a division of legal responsibility for regulating transgenic plants. The U.S. EPA has the lead for 
Transgenic plants: learning from the regulation of other technologies

evaluating health and environmental effects of transgenic plants that produce pesticidal substances under the authority of the Federal Insecticide, Fungicide and Rodenticide Act. The U.S. Food and Drug Administration is responsible for reviewing any potential health effects of nonpesticidal transgenic plants that produce pharmaceuticals under the Food, Drug and Cosmetic Act (although the USDA appears to have the authority to issue permits for field testing plants that produce pharmaceuticals). The U.S. Department of Agriculture's Animal and Plant Health Inspection Service (APHIS) has authority to assess "the potential effects of nonpesticial transgenic plants on other plants and animals in both agricultural and nonagricultural environments" (NRC, 2002, p 19). Thus, APHIS is largely responsible for regulating transgenic plants that pose risks of adverse environmental or ecological harms as well as risks to other agricultural crops. Assessment of this regulatory authority in light of the NRC report and the preceding discussion of this paper is the limited focus of the remainder of the paper.

In light of the discussion above, the U.S. has adopted the more protective of the two generic legal strategies for transgenic plants. The legal structure is generically a premarket screening structure, requiring some degree of review and assessment of transgenic plants before importing the plants into a population, transporting potential plant pest in interstate commerce, or releasing them into the environment or putting them into commercial production (NRC, 2002, pp 104, 106). It is a "tiered" legal structure with quite minimal review for plants that, on the basis of submitted evidence, appear to pose no risks to the environment or other crops and more elaborate review of transgenic plants that pose greater risks. This structure thus burdens innovation differentially, depending upon the properties of the plants involved. Transgenic plants are considered "new organisms" introduced into the environment "because they potentially have new ecological characteristics that could make them plant pests" (NRC, 2002, p 104).

Under the authority of two statutes APHIS has issued regulations to guide the assessment of risks from transgenic plants under three different regulatory processes for which manufacturers must seek approval: "Notification", "Permitting" and "Petitions for Nonregulated Status".

\section{Notification}

The vast majority of transgenic plants are reviewed under a streamlined "notification" system, the "tier" requiring minimal review of new plants and only minimally burdening innovation for plants satisfying the requirements of this process. The notification process requires a proponent of the transgenic plant to "notify APHIS of its intent to release a regulated article" (NRC, 2002, p 108). The application with appropriate data attached is reviewed by one member of the scientific staff for whether it qualifies under the notification program and whether it is complete. This scientist has only 30 days for review, and then must make a recommendation to the appropriate state officials about whether, on the basis of the data in the application, the state should permit the proponent to release the plant (NRC, 2002, p 108). This process is "not subject to external scientific review or any other public input" (NRC, 2002, p 108).

To be eligible for the notification procedure the plant must not be listed or considered as a "weed" according to a federal "weed" list, the DNA function must be known and not result in plant disease, and the DNA must be stable so that the trait is "inherited in a Mendelian fashion for at least two generations" (NRC, 2002, p 108). Moreover, the inserted DNA must not produce an infectious entity, encode substances that might be toxic to other species or those that might feed on the plant, or produce products "intended for pharmaceutical use" (NRC, 2002, p 108). Finally, the DNA must not "be derived from human or animal viral pathogens or other potential human or animal disease-causing agents" and "virus derived sequences must be known noncoding regulatory sequences" or unlikely to produce or facilitate viruses and their spread in plants (NRC, 2002, p 109).

In addition there are various handling and performance standards for cultivation, transportation, and storage that petitioners must follow to ensure the plant and its progeny will not escape or persist in the environment. Once a plant has met the requirements under the notification program, a permit for field-testing is not required for one year from the date of introduction (NRC, 2002, p 108).

In general this procedure appears to assume that the genetic properties of the plant are well understood, stable, not carried by vectors that might easily transfer to infect humans or animals. Moreover, plants subject to the notification procedure are subject to the least regulatory review, spend minimal time in product review, have little time-delay between submission and approval and experience the least interference with product development. However, there are concerns both with the regulatory basis of regulation and with the underlying science.

As the Academy notes, if a plant properly qualifies for the notification process and "the applicant complies 
with the performance standards, environmental impacts should be minimal ..." (NRC, 2002, p 178). However, there are several problems with this process.

(1) The first is a conceptual problem. A single federal list of weeds or "noxious plants" is inadequate to determine whether a transgenic plant would identify all such plants that would pose problems in particular locales (NRC, 2002, pp 178, 179). Plants become invasive pests because of local conditions, other plants and the environment around them, thus a single list of weed characteristics, not sensitive to local contexts poses problems according to the NRC. Moreover, there is "excellent scientific evidence" showing that the criteria utilized to determine the federal list "are inadequate ex ante predictors of weediness ... [y] et APHIS continues to use these criteria in decision making" (NRC, 2002, p 179).

(2) A second issue concerns the pragmatic inadequacy of testing conditions. There are no limits on the acreage of plants grown after approval under the notification process, yet since "many ecological effects are scale dependent and more likely to occur at larger spatial scales, these considerations raise concerns about acreage limitations" (NRC, 2002, p 179). In addition, as the size of plantings increases, it becomes more difficult for APHIS to ensure that various performance standards aimed at confining the transgenes are complied with (even if the agency has sufficient personnel to review compliance (an additional problem)) (NRC, 2002, p 179).

(3) Transgenic plants that are toxic to other species are not reviewed under the notification process (they are legally required to be tested under the more stringent "permitting" process). Yet there was at least one quite significant mistake in which such a plant was approved under notification (NRC, 2002, p 182).

(4) A more general issue is informational in nature, similar to some that obtain in the regulation of chemical substances. It is difficult for APHIS to determine that a plant is not toxic to non-target species, because too little information "must be provided by applicants." (NRC, 2002, p 182). To better review transgenic plants on this dimension more information must be provided.

(5) There are also some other pragmatic shortcomings since the notification process provides little time for agency review and there is a shortage of personnel to review applications and to inspect field sites (a typical problem for under-funded agencies). Together these pose serious problems of adequate review and inspections (NRC, 2002, pp 180-182). Thus, even if the process were in principle capable of identifying all transgenic plants that might pose problems, the required rapid review and shortage of personnel puts these goals in jeopardy.
Finally, there are three generic critiques of the notification process. First, petitions to utilize the notification process are not published in the Federal Register, thus denying the public and external scientists information about substances for which approval is sought. Second, since determining whether a plant qualifies for streamlined notification approval is decided by a single agency scientist, the Academy believes there is too little external scientific input into and external checks on the process (NRC, 2002, p 176). Third, under provisions for "confidential business information" (CBI) "all manner of data are hidden from public view and even from independent scientific scrutiny" (NRC, 2002, p 177). Such provisions even prevented the NRC itself from providing "an independent scientific assessment of APHIS rulings because of the broad use of CBI" (NRC, 2002, p 177). "Public credibility is eroded when the same information marked CBI under APHIS documents is not considered CBI and is open to public inspection in other jurisdiction such as Canada or Europe" (NRC, 2002, p 177). Fourth, although notification was designed only for "field trials," plants that create commercial products can be grown under notification procedures with its minimal information requirements (NRC, 2002, pp 180181).

Against the background of problems revealed by the experience of synthetic chemical regulation, what problems might be anticipated by the notification procedures? Although there is a place for a comparatively quick review of transgenic plants when there is good evidence that they will not pose problems, the existing procedures appear to have features that undermine the goals of the existing regulatory structure. Moreover, there appears to be a need for better scientific and regulatory guidance to demarcate which transgenic plants should be routed through the notification procedure and which should be screened under the permit process. That is, a bi-furcated or tri-furcated regulatory structure - with some products receiving modest or no regulatory scrutiny while others receive much more detailed attention - will only function well to serve both risk minimization and innovation, if there are wellfounded scientific grounds for distinguishing between which products to screen carefully and which to screen minimally or not at all. Without a good basis for demarcation, the notification procedure risks permitting products into the market that could cause serious problems. A too rapid a review by too few scientists with no external checks on the quality and rigor of the review undermines the pre-market and protective aims of the current regulatory structure for a new and not fully 
Transgenic plants: learning from the regulation of other technologies

understood technology. Better scientifically well founded and accurate demarcation criteria appear to be needed to separate which plants go through notification and which through the permit process (NRC, 2002, p 9). Finally, even if the process worked reasonably well, it could be put at risk by lack of controls on the scale of plantings.

\section{Permitting}

The second regulatory program under APHIS is permitting. This is utilized for the "movement, importation and field testing of transgenic plants that do not qualify for notification" e.g., for commercial pharmaceuticalproducing plants, for plants denied permits under the notification program, or for plants that appear to pose greater environmental risks than those considered under notification. Since the permitting program is an alternative to notification, it legally presumes that a plant is a "potential pest and requires anyone who wants to introduce it into the environment to obtain a permit" (NRC, 2002, p 110). Thus, notification is reserved for plants that do not appear to pose environmental problems, while the permitting process is utilized for transgenic plants for which such assumptions cannot be ensured.

The permitting process is more elaborate, requires more detailed information and provides "detailed guidance for permit applications." The required information must include data to ensure that "the transgenic plant can be adequately characterized", that transgenic material will not persist in the environment, that unintentional or unanticipated effects, if any, can be adequately confined, and that there must remain no effects from field testing after the test has been terminated (NRC, 2002, $\mathrm{p}$ 110). With this more detailed review of transgenic plants APHIS scientists have 120 days to review an application before a new plant is released into the environment and can stop the "clock" if additional information is needed.

This procedure is rarely utilized. As of the spring of 2001 only one transgenic plant was "grown to produce a commercial product" under this process, but the process is expected to grow dramatically with the number "pharmaceutical" plants grown in the field (NRC, 2002, p 110). However, at the present time since fewer plants are addressed under permitting, all field sites tend to be inspected (NRC, 2002, p 183).

Generic problems resemble several of those under notification. (a) There are no acreage limits on plantings. (b) Only about $6 \%$ of permit applications are listed in the Federal Register (only those requiring an Environmental Assessment), thus denying external scientists and the general public the opportunity for feedback on $94 \%$ of the plants approved for importation, movement or fieldtesting under this program. (c) Feedback would nevertheless be limited because the confidential business information exclusion might preclude consideration of critical information. (d) The agency needs to do a better job demarcating transgenic plants that should be considered under notification and those under permitting (NRC, 2002, p 183).

\section{Petitions for nonregulated status}

The final procedure under APHIS is one in which the agency can determine "that a particular transgenic plant is not a regulated article - that is, that it does not fall under the definition of a plant pest" (NRC, 2002, p 111). It is also the "sole route for commercialization of transgenic plants (e.g., sale of transgenic soybean seed) and the primary but not sole route to commercialization of transgenic plant products (e.g., when the plants are never sold but a product such as an industrial protein extracted from the plant is sold)" (NRC, 2002, p 111).

Extensive information is required to be generated by the petitioner and submitted to obtain approval for "nonregulated status" (summarized at NRC, 2002, pp 112118) (APHIS may request additional information). The information is utilized to determine whether the regulated article displays any plant pathogenic characteristics; whether it is less likely "to become a weed than its nontransformed parent; [whether it] is unlikely to increase the weediness of cultivated, feral, or wild-related plants; [whether it damages] processed agricultural commodities; and [whether it may] . . cause unintended significant harm in other organisms" (NRC, 2002, p 112).

Once a transgenic plant has been granted nonregulated status under this procedure APHIS "cannot exercise any additional oversight on the plant or its descendants" (NRC, 2002, p 112 (emphasis added)). Descendants of such plants might include all plants of the same species that might receive the transgene through sexual reproduction, but may also include quite distantly related members of the same crop species. Thus, separately deregulated plant lines could be interbred and could combine different transgenes in the resulting offspring. The progeny plants would not be subject to APHIS regulation (NRC, 2002, $\mathrm{p} 111$ ). (However, there is some belief that the agency could intervene after the fact of regulatory approval, if serious problems developed (Ellstrand, 2003)). Although decisions to deregulate transgenic plants are done case-by-case, the agency has deregulated "dozens of genetically modified 
crops" (NRC, 2002, p 112) and by the date of this paper may approach one hundred (Ellstrand, 2003).

This process should better protect against risks and it does increase the burdens on innovation. Nonetheless, the NRC has substantial concerns about the nonregulated status procedure, even though transgenic plants receive a heightened review under it. Because after deregulation APHIS may exercise no further oversight, the process is more thorough than for other processes within APHIS concerning transgenic plants. However, after reviewing six petitions for nonregulated status NRC found that this procedure "should be made significantly more transparent and rigorous by enhanced scientific peer review, solicitation of public input, and development of determination documents with more explicit presentation of data, methods, analyses and interpretations" (NRC, 2002, p 10 (emphasis added)). Although, the NRC found that none of the six petitions reviewed resulted in mistakes, the committee appears not have sufficient confidence that the current process would prevent mistakes. The NRC's concerns here seem well founded for two major reasons. First, because in the NRC's judgment both genetics and ecology are not well understood, the review process should be more rigorous when scientists are making decisions under such great uncertainty. Second, the first reason is enhanced because the decision appears to be made in perpetuity suggesting that it is not reviewable (although as suggested above some believe it could be reviewed). The more nearly irrevocable a decision is, the greater basis one should have to ensure that it is correct. Such conclusive decisions need to be approached quite cautiously, and even more so when the two most pertinent areas of science are still developing.

Beyond the above issues, there are others specific to non-regulated status as well as more general issues of concern to the NRC.

(1) The Committee, recognizing that scientific understanding of both "genetics and ecology is still developing", notes the importance of a case-by-case assessment of each plant considered for non-regulated status because "each plant/trait/environment combination is different" (NRC, 2002, p 184). Thus, the agency should resist a simple check list approach to reviewing submitted information (NRC, 2002, p 185). Even though a simple check list might result in quicker reviews, the NRC seems concerned that greater care should go into reviewing substances that will end up in non-regulated status.

(2) Moreover, the agency should require information on "full DNA sequences to transgenes as they are integrated in the plant genome" (NRC, 2002, p 186) in order to ensure that the transgenes do not express themselves in ways that "have negative consequences" (NRC, 2002, p 185).

(3) Currently, APHIS appears not to have requirements for the kind and amount of evidence needed to match "the potential level of hazard and risk" (NRC, 2002, p 187). In effect, the agency appears not to require more and better evidence for greater risks, in order to have assurances that the risks will not materialize. This would seem to be a minimal requirement for risk assessment.

(4) Small scale test plots (utilized to assist in identifying any risks or adverse consequences from transgenic plants) are inadequate to determine ecological and non-target organisms effects from large-scale plantings (NRC, 2002, pp 188, 189). (And, field testing needs to be more comprehensive in order to try to detect effects on invertebrates and other biota. (NRC, 2002, $\mathrm{p}$ 189)). This is analogous to, but much more serious than, concerns with testing pharmaceutical drugs in small clinical trials - they are inadequate to detect adverse effects in large biologically diverse human populations (Green, 2000). Of course, it is important to recognize that there will always be some residual risk of mistakes when testing is in effect based upon smaller samples than the size of the ultimate release. However, if such testing is well-motivated and conscientiously performed with the best scientific input, this is a risk it is reasonable for a society to take.

(5) An analogous worry is that testing some of the byproducts of transgenic plants for toxicity at high doses (similar to toxicity testing for humans), is inadequate to determine any risks or adverse effects from long-term, low-level exposure in complex ecosystems (NRC, 2002, p 189).

\section{More generic concerns about transgenic plants}

The NRC has several concerns that go beyond specific legal structures and agency practices. First, in reviewing plants for their effects on ecosystems, APHIS is only obligated to consider "environmental impacts of deregulated genetically modified organisms [within] the confines of the United States" although on occasion it has considered gene flow outside the U.S. (NRC, 2002, $\mathrm{p}$ 176). Yet other countries, such as Mexico, might be where gene outflows occur with potentially serious adverse effects in such different environments. The NRC is, thus, concerned that plants approved for release only within the U.S. will be transported across national borders where they could pose substantial problems. 
Transgenic plants: learning from the regulation of other technologies

Even within the U.S., APHIS and the EPA have been inconsistent in approving locations for planting transgenic plants. The agency needs to have a more subtle regulatory approach to approving plants with respect to geographic location, since what may be permissible in one location could cause serious problems elsewhere (NRC, 2002, p 185).

Second, the NRC has a consistent generic concern about the extent of external scientific and public input into the regulatory process and often there is not the proper fit between expertise needed to assess risks and agency personnel to do the analysis. This is manifested in several ways. (a) There is little notification to the public and external scientific community concerning transgenic plants under review. (b) For changes in regulatory procedure the NRC recommends APHIS do something it has not routinely done in the past, namely, "convene a scientific advisory group" a common practice at other agencies (NRC, 2002, p 10). (c) For "specific, precedentsetting decisions" APHIS should "solicit broad external scientific review well beyond the use of Federal Register notices" ((Emphasis added) (NRC, 2002, p 10)). This recommendation is aimed at both broader public discussion of any such precedents and certainly greater scientific input than would be received by an agencyconvened science advisory panel and any input from interested scientists. (d) The NRC is quite sensitive to the need for broad technical support for scientific decisions that must be made, as well as to the need for the public legitimacy that comes from the public having an opportunity to participate in and understand regulatory decisions that affect their lives. On these two dimensions, the NRC appears to be concerned that the current scientific reviews of transgenic plants under any of the regulatory processes are not sufficiently accurate to ensure that there will not be inadvertent releases of noxious plants in the future that will harm other agricultural crops or that will damage natural ecosystems. The NRC generic recommendation for greater scientific and public involvement may be too weak. A few other public bodies that have addressed similar issues have argued that for genuine and sustained broader public involvement, agencies must find ways to support some stakeholders who have difficulty finding the time or the resources to invest the extensive time and effort it takes to participate in public discussions of regulatory impacts. Thus, while providing greater opportunities is a first step, providing more tangible support for such public involvement may be needed.

A third generic issue concerns monitoring in connection with transgenic agricultural plants: validation and quality control monitoring, plus much broader environmental monitoring. In order to assess the success and quality of pre-commercial assessment of risks there are compelling arguments "for validation-testing and ecological monitoring after commercialization of [transgenic] plants" (NRC, 2002, pp 12, 13). It is nearly impossible to detect many environmental risks that would result from large-scale commercialization by means of small-scale experiments, e.g., "a small-scale field experiment is unlikely to detect $10 \%$ population reductions in non-target species" yet these can be "significant" (NRC, 2002, $\mathrm{p}$ 194). Moreover, pre-approval testing is not likely to detect "low-probability events and low-magnitude effects" such as invasion of nearby ecosystems (NRC, 2002, pp 194, 195). Furthermore, since ecosystems are complex, it is difficult for small-scale experiments to replicate biological perturbations in them.

Validation monitoring is an obvious part of judging the quality and accuracy of pre-approval assessment procedures (NRC, 2002, p 194). Such monitoring would be aimed at detecting risks related to the "movement of transgenes", impacts of whole plants that might escape, effects on non-target species and the evolution of resistance (NRC, 2002, p 196). However, "monitoring cannot substitute for precommercialization regulatory evaluation" (NRC, 2002, p 14). If post-commercial monitoring were substituted for pre-commercial assessment of transgenic plants, this would tend to put the review of transgenic plants in the same place as post-market evaluation of synthetic chemical substances, a process that has had some notable problems and a process that is far from a precautionary approach to protecting human health and our environmental resources.

The need for environmental monitoring of the effects of transgenic plants is merely part of a much larger and more serious problem that should be addressed to reduce risks to human health and the environment (Cranor, 2003b). The problem the NRC identifies is that " $[\mathrm{t}] \mathrm{he}$ U.S. does not have in place a system for environmental monitoring of agricultural and natural ecosystems that would allow for adequate assessment of the status and trends of the nation's biological resources" (NRC, 2002, pp 14, 193). Lack of long-term monitoring of ecosystems greatly hampers any effort to identify the general impacts of agriculture on ecosystems or the any impacts of new transgenic crops on ecosystems, traditional agricultural crops or human health. Yet for those who care about our natural environment, existing farm environments and human health, protecting them suggests that there should be much greater environmental and human health monitoring for long-term effects. 
Long-term monitoring provides the necessary data to develop indicators and to model annual recruitment that are then easily measured and used in management decisions. . . [and to] provide baseline information necessary to evaluate whether changes in management or other environmental variables result in population changes. However, for most biological resources such long-term data do not exist (NRC, 2002, p 202).

Finally, the "environmental monitoring of agricultural and natural ecosystems in place in the United States is inadequate for assessing the potential impacts of commercialized transgenic crops" (NRC, 2002, p 218).

\section{TAKING STOCK}

The existing regulatory structure at the USDA for transgenic plants, although generically a pre-market structure and holding the promise of better detecting risks that can arise than would post-market laws, appears to be in need of improvement in order to assess and identify the range of risks that could easily arise from transgenic plants. Indeed the NRC's discussion, couched in the lowkey, cautious language of science represents considerable criticism of these nominally more protective existing regulatory structures and practices. And, according to the NRC these structures appear to fall short of serving the public health and the environment as well as they could for a new and poorly understood technology. If the NRC recommendations are not heeded, it appears that the regulatory structure for assessing transgenic plants has the potential to miss substantial problems and these might well be amplified because of the potential for living things to procreate, mutate, and migrate.

Even if some of the NRC recommendations were followed completely with full governmental support and resources, there remain areas for improvement. There appear to be no provisions for company monitoring and reporting of adverse effects from their products to assist in catching any regulatory mistakes. (Recall some of the problems with the regulation of chemical products.) There appear to be no provisions for rapid removal of products from the market that cause adverse effects or for reduction in adverse reactions (the procedures may be worse for transgenic plants that have received "nonregulated status" than for synthetic chemicals). Such provisions that even good post-market laws would have would help minimize harm that might occur. Indeed once a plant has "nonregulated status," APHIS's authority over it seems quite limited. Theoretically, the agency could take authority over a problematic plant, if it were officially classified as a "weed", but whether this would occur is much less clear.

If the NRC recommendations were fully implemented and we also learned from the chemical regulatory experience, the U.S. would have taken some steps toward a reasonable, tiered, pre-market approach for reviewing the risks from transgenic plants that are introduced into a world that has already suffered a number of environmental insults (when the sciences of ecology and genetics are still developing). (There may be some time in the future when both sciences are sufficiently understood to permit some products to be subject to post-market regulation, but it appears that that day has not arrived). As citizens we can only hope that the NRC report will be fully heeded, implemented, financially supported, and ultimately improved upon to better implement the existing legal structure so that we can receive the benefits from transgenic plants with fewer risks. Whether it will be or not remains to be seen.

\section{ACKNOWLEDGEMENTS}

This paper was written while the author was funded by research grants from the National Science Foundation (NSF \# 99-10952), the University of California Toxic Substances Research and Teaching Program, and a UC Intramural Grant. I am grateful to Norman Ellstrand, Department of Botany and Plant Sciences and a member of the National Research Council Committee that wrote The Environmental Effects of Transgenic Plants, for valuable comments on this paper.

Received August 7, 2003; accepted January 5, 2004.

\section{REFERENCES}

Bailor JC (2002) Personal communication at Collegium Ramazzini

Berger MA (1997) Eliminating general causation: notes towards a new theory of justice and toxic torts, Columbia Law Review 97: 2117-2152

Brown LR, Flavin C, French H (2000) State of the world 2000, New York, WW Norton, Co

Cranor CF (1993, 1997) Regulating toxic substances. New York, Oxford University Press

Cranor CF (1999) Asymmetric information, the precautionary principle and burdens of proof in environmental health protections. In Raffensperger C, Tickner J, eds, Protecting public health and the environment: Implementing the precautionary principle, Washington DC, Island Press, pp 74-99 
Transgenic plants: learning from the regulation of other technologies

Cranor CF (2003a) Some legal implications of the precautionary principle, Eur. J. Oncology 2: 31-51

Cranor CF (2003b) What could precautionary science be? Research for early warnings and a better future. In Tickner J, Precaution, environmental science, and preventive public policy, Island Press, Washington DC, pp 305-319

Eastmond DA (2002) Personal communication

Ellstrand NC (2001) When transgenes wander, should we worry?, Plant Physiol. 125: 1543-1545

EPA, EDF, CMA agree on testing program targeting 2800 chemicals, Envtl. Health Letter Silver Spring, MD, Business Publishers, Inc., Oct 1998, 37: 193

Ellstrand NC (2003) Personal communication

European Environmental Agency (2001) Late lessons from early warnings: The precautionary principle, Copenhagen, pp 1896-2000

Green MD (2000) Safety as an element of pharmaceutical quality: the respective roles of regulation and tort law, St. Louis U. Law J. 42: 163-190

Huff J, Melnick R (2002) Chemical carcinogenesis bioassays: critical for the sensible application of the precautionary principle for protecting public health. Presentation to Collegium Ramazzini, October 23-24, 2002
Lubchenco J (1998) Entering the century of the environment: A new social contract for science, Science 279: 491-497

Markowitz G, Rosner D (2002) Deceit and denial: The deadly politics of industrial pollution, Berkeley, University of California Press

National Research Council (1984) Toxicity testing: strategies to determine needs and priorities, Washington DC, National Academy Press

National Research Council (2002) Environmental effects of transgenic plants: the scope and adequacy of regulation, Washington DC, National Academy Press

Rodgers WH Jr. (1994) Environmental law, 2nd edn, Minneapolis, MN, West Publishing, Co

Sears MK, Hellmich RL, Stanley-Horn DE, et al. (2001) Impact of $B t$ corn pollen on monarch butterfly populations a risk assessment, Proc. Natl. Acad. Sci. 98: 11937-11942

US Congress, Office of Technology Assessment (1987) Identifying and regulating carcinogens. Washington DC, US Government Printing Office

US Congress, Office of Technology Assessment (1995) Screening and testing chemicals in commerce. Washington DC, US Government Printing Office

To access this journal online: www.edpsciences.org 